\title{
Atores, canais de comercialização e consumo da mangaba no nordeste brasileiro
}

\author{
Dalva Maria da Mota ${ }^{1}$ \\ Heribert Schmitz ${ }^{2}$ \\ Josué Francisco da Silva Júnior ${ }^{3}$
}

Resumo: O objetivo deste artigo é analisar processos que vão do extrativismo ao consumo da mangaba, enfatizando os diferentes atores em cena, as suas relações, os canais de comercialização e as características do consumo. A pesquisa foi realizada no nordeste do Brasil (BA, AL, SE e PE), por meio de métodos qualitatitivos e quantitativos. Os principais resultados mostram uma fraca tendência de domesticação para atender à demanda crescente do mercado e ameaças ao extrativismo por fatores externos.

Palavras-chave: Populações tradicionais, Hancornia speciosa Gomes, frutas tropicais, mangabeiras.

\section{Classificação JEL: Z100}

Abstract: The aim of this article is to analyse the processes which begins from raw material extraction to the consumption of mangaba, emphazising different actors, their relationships, marketing channels, and

\footnotetext{
${ }^{1}$ Doutora em Sociologia, Pesquisadora da Embrapa Amazônia Oriental, Belém-PA, Bolsista de produtividade do CNPq; dalva@cpatu.embrapa.br

${ }^{2}$ Doutor em Ciências Agrárias, Professor de Sociologia, Universidade Federal do Pará (UFPA), Belém-PA, Bolsista de produtividade do CNPq; heri@amazon.com.br ${ }^{3}$ Mestre em Fruticultura Tropical, Pesquisador da Embrapa Tabuleiros Costeiros, Aracaju-SE; josue@cpatc.embrapa.br
} 
consumption characteristics. The research was carried out in the Northeast of Brazil (Brazilian states of Bahia, Alagoas, Sergipe and Pernambuco) using quantitative and qualitative approaches. The main results indicated weak domestication of mangaba trees to attend to an increasing market demand, and threats to extractivism by external factors.

Keywords: Traditional populations, Hancornia speciosa Gomes, Tropical fruits, Remaining areas of mangaba trees.

JEL Classification: Z100

\section{Introdução}

É consenso entre os estudiosos das diferentes áreas do conhecimento que a globalização tem afetado de forma desigual e heterogênea as esferas da produção, da distribuição e do consumo e, conseqüentemente, as relações sociais que aí se dão em diferentes partes do planeta, gerando novas formas de desigualdades. Autores como Bonanno et al. (1994), Friedland (1994), Cavalcanti $(1995,1999)$ e Marsden (1999) têm trabalhado essa problemática, analisando suas múltiplas implicações, dentre as quais: 1) tendência de homogeneização das formas de consumo; 2) tráfego de alimentos exóticos, tornando-os familiares nos diferentes lugares do mundo numa velocidade e padronização nunca antes experimentada; 3) dissociação entre lugares de produção e de consumo; 4) emergência de grupos de consumidores altamente preocupados com a ingestão de produtos saudáveis e frescos. Paralelamente, no entanto, co-existem a adoção de padrões de consumo nocivos que têm ocasionado graves problemas de saúde pública (são exemplos a obesidade e o aumento das taxas de colesterol em crianças).

Apesar do reconhecimento das transformações em curso, concordamos com Cavalcanti (2003), que afirma: "Observa-se uma tendência à superestimaçäo do papel transformador da globalização, mais do que à dinâmica de jogos de forças que têm lugar em distintas situações”. Além disso, as diferentes formas de produção e reprodução social nem sempre são evidenciadas como eventos globais, e muito menos como produtos direcionados para consumidores exigentes. Esse é o exemplo de muitos 
dos produtos oriundos do extrativismo que circulam estritamente em mercados locais e regionais e, mesmo assim, satisfazem às necessidades de subsistência de numerosos grupos na América Latina, além de desempenhar papel vital no comércio local e na reprodução social de grupos em desvantagem como mulheres e crianças (Shanley et al., 2002).

Mesmo que nesse atual contexto seja visível o domínio crescente das grandes corporações transnacionais da produção à distribuição de alimentos, co-existem circuitos com dinâmicas completamente diferentes. Nesses, há produtos e atores vinculados a mercados regionais e locais. Esses fazem parte de redes de relações sociais bastante distintas, que tanto podem se basear em vínculos legais e duradouros, como em relações precárias ou mesmo de caráter familiar, como é o caso do extrativismo em diferentes partes do Brasil e do mundo.

Embora esses produtos tenham condições de produção, distribuição e consumo tão diferenciadas e particulares, eles compõem a pauta de consumo de populações cada vez mais distantes e sedentas por novidades que atendam aos apelos persuasivos da publicidade na denominada “aldeia global” (McLuhan, 1962). Esse é o caso das frutas tropicais e, em menor escala, das nativas como a mangaba ${ }^{4}$. Oriunda predominantemente do extrativismo praticado pelas mulheres e ainda relativamente livre dos requisitos dos produtos segundo as preferências dos consumidores, ela é item de consumo fundamental para a população litorânea nordestina, seja na tradicional forma de suco, seja como sorvete e picolé e, mais recentemente, como sobremesa (mousse e pudim) e como drinque. ${ }^{5}$

Nesse contexto de complexas, heterogêneas e contraditórias tendências de produção e de consumo, a questão que se coloca é: como essas populações continuarão a ter acesso a um recurso que, apesar de valorizado no consumo regional, está pressionado pela especulação imobiliária que ameaça expulsar os nativos e destruir as áreas remanescentes? Sem contar que a comercialização das frutas se dá por meio de uma cadeia repleta de informalidades e vulnerabilidades, em um mercado que tende a exigir padronização. Nesse sentido, o objetivo deste trabalho é

${ }^{4}$ Mangaba é o fruto da mangabeira (Hancornia speciosa Gomes) e importante matériaprima para a agroindústria de frutas tropicais do Nordeste e Centro-Oeste do Brasil.

${ }^{5}$ Mangabarosca é um drinque popular nas cidades litorâneas do Nordeste, cujos ingredientes incluem mangaba, vodca ou cachaça, açúcar e gelo. 
analisar processos particulares que vão do extrativismo ao consumo, valorizando os diferentes atores em cena e suas relações, os canais de comercialização e as características do consumo.

\section{Metodologia}

A pesquisa foi realizada por meio de levantamento de dados secundários, observação participante, realização de transects e de entrevistas estruturadas e semi-estruturadas com diferentes atores que participam do extrativismo, processamento, comercialização e consumo da mangaba no litoral dos seguintes estados da região Nordeste: Bahia, Sergipe, Alagoas e Pernambuco.

As observações tiveram o intuito de identificar práticas associadas a essas atividades, e foram realizadas nos locais em que elas ocorrem (remanescentes de mangabeiras, pontos onde se dá a coleta e residências das catadoras no decorrer dos serviços de pós-colheita e processamento). Nessas ocasiões, foram efetuados registros em diário de campo e em fotografias.

Os dados secundários foram buscados em estatísticas preexistentes e, de modo geral, representam um problema pelo fato de serem limitados e de não corresponderem ao que se observa em campo, provavelmente por serem coletados independentemente do momento em que se dá a safra. De toda forma, agregando dados e informações de diferentes origens, buscou-se compor um quadro geral quantitativo que facilitasse a compreensão dos processos que interligam os diferentes atores.

Os transects se deram em quatro diferentes povoados, sendo um em cada estado visitado, para comparar as diferentes formas de manejo e conservação dos recursos em sua relação com as populações tradicionais.

As entrevistas tanto foram realizadas após as observações, quanto em ocasiões informais em que as pessoas eram encontradas em suas residências ou em algum outro espaço da localidade ou da cidade. Tiveram como objetivo levantar visões individuais sobre o extrativismo, acesso aos recursos, comercialização, etc. Em algumas ocasiões, juntamente com o entrevistado, eram traçados desenhos relativos aos circuitos entre o campo e o mercado. Homens e mulheres catadores 
de mangaba, comerciantes, processadores e consumidores foram entrevistados.

O conjunto dos entrevistados foi composto por quatro grupos: 1) catadores de mangaba (mulheres, homens e crianças) que se dedicam exclusivamente a atividades extrativistas (mangaba, produtos do manguezal, pesca e artesanato) com diferentes níveis de integração com o mercado; 2) intermediários e comerciantes de mangaba e de outros produtos; 3) processadores; e 4) consumidores. Em todos os grupos, as variáveis gênero e território, foram critérios de classificação e seleção dos entrevistados.

Foram entrevistadas 86 pessoas $^{6}$ que de formas diferenciadas participam do extrativismo da mangaba, sendo que dez são simultaneamente catadoras, vendedoras e habitantes dos povoados identificados na Tabela 1.

As informações e dados foram sistematizados em quadros-sínteses, segundo os grandes temas selecionados, que são: extrativismo e globalização, acesso aos recursos, formas de interação entre os atores, dinâmicas de comercialização, gestão de recursos naturais, etc.

Um estudo de caso $^{7}$ foi realizado no Povoado Pontal, uma das áreas de Sergipe que apresenta uma boa conservação dos remanescentes, com o intuito de observar em profundidade as formas de interação dos diferentes atores envolvidos nos processos.

A pesquisa está sendo realizada desde 2003 (Mota et al. 2003, 2005; Mota e Silva Júnior, 2003, Silva Júnior et al., 2003), sendo que a etapa a que se referem as análises aqui efetuadas foi realizada no decorrer de 2005 em áreas costeiras dos quatro estados (Bahia, Sergipe, Alagoas e Pernambuco).

\footnotetext{
${ }^{6}$ Selecionadas segundo as diferentes relações que têm com o extrativismo e a comercialização da mangaba em um universo ainda desconhecido. Privilegiamos a entrevista com amostra dirigida, também para realizá-la em profundidade.

${ }^{7} \mathrm{O}$ estudo de caso permite explicar situações particulares em profundidade. Via de regra, trata-se do estudo de uma unidade de análise que pode ser um sujeito particular, uma instituição ou uma situação específica para compreendê-la como uma unidade, muitas vezes por meio da análise dos fenômenos típicos do mundo social em questão. No âmbito dessa abordagem, podem ser utilizados diferentes métodos. Os resultados não pretendem ser generalizantes, mas explicativos em profundidade (Lamnek, 1995; André, 2000).
} 
Tabela 1. Localidades visitadas e entrevistas

\begin{tabular}{|c|c|c|c|}
\hline Estado & $\begin{array}{l}\mathrm{N}^{\circ} \text { de } \\
\text { Entre- } \\
\text { vistas }\end{array}$ & Municípios & Localidades Visitadas \\
\hline \multirow{4}{*}{ Bahia } & \multirow{4}{*}{16} & Conde & $\begin{array}{l}\text { Sítio do Conde, Barra do Itariri, Naipos, Cobó, } \\
\text { Massaranduba }\end{array}$ \\
\hline & & Mata de São João & $\begin{array}{l}\text { Imbassaí, Barro Branco, Diogo, Praia do Forte, } \\
\text { Areal, Sauípe }\end{array}$ \\
\hline & & Esplanada & Baixios \\
\hline & & Jandaíra & Costa Azul \\
\hline \multirow{6}{*}{ Sergipe } & \multirow{6}{*}{27} & Indiaroba & Pontal, Preguiça, Convento, Terra Caída \\
\hline & & Itaporanga d'Ajuda & Ilha Mem de Sá \\
\hline & & Aracaju & Terra Dura \\
\hline & & $\begin{array}{l}\text { Nossa Senhora do } \\
\text { Socorro }\end{array}$ & Taiçoca de Dentro \\
\hline & & Barra dos Coqueiros & Olhos d’Água, Capuã, Sítio Lopes, Jatobá \\
\hline & & Pirambu & Aningas, Lagoa Redonda, Pau Seco, Alagamar \\
\hline \multirow{11}{*}{ Alagoas } & \multirow{11}{*}{25} & Coruripe & $\begin{array}{l}\text { Miaí de Baixo, Miaí de Cima, Lagoa do Pau, } \\
\text { Poxim, Pituba, Pontal do Coruripe }\end{array}$ \\
\hline & & Jequiá da Praia & Barra do Jequiá \\
\hline & & Marechal Deodoro & Barra Nova, Ilha de Santa Rita \\
\hline & & Barra de São Miguel & Barra de São Miguel \\
\hline & & Maceió & Ipioca \\
\hline & & $\begin{array}{l}\text { Barra de Santo An- } \\
\text { tônio }\end{array}$ & Barra de Santo Antônio \\
\hline & & Passo de Camaragibe & Barra de Camaragibe, Marceneiro \\
\hline & & $\begin{array}{l}\text { São Miguel dos Mi- } \\
\text { lagres }\end{array}$ & Toque \\
\hline & & Porto de Pedras & Curtume \\
\hline & & Japaratinga & Bitingui, Boqueirão, Japaratinga, Sítio Paraiso \\
\hline & & Maragogi & $\begin{array}{l}\text { Barra Grande, Ponta de Mangue, Peroba, } \\
\text { Tábua Rachada }\end{array}$ \\
\hline \multirow{6}{*}{$\begin{array}{l}\text { Pernam- } \\
\text { buco }\end{array}$} & \multirow{6}{*}{18} & Tamandaré & Tamandaré, Carneiros \\
\hline & & Ilha de Itamaracá & Vila Velha, Oiteiro \\
\hline & & Goiana & $\begin{array}{l}\text { Gambá, Gulandim, Ponta de Pedras, Tabatinga, } \\
\text { Riacho Doce, Carne de Vaca }\end{array}$ \\
\hline & & Sirinhaém & Barra de Sirinhaém, A-Ver-o-Mar, Guadalupe \\
\hline & & Ipojuca & $\begin{array}{l}\text { Porto de Galinhas, Muro Alto, Maracaipe, } \\
\text { Serrambi, Engenho Canto, Toco, Toquinho }\end{array}$ \\
\hline & & $\begin{array}{l}\text { Cabo de Santo Agos- } \\
\text { tinho }\end{array}$ & Nazaré, Gaibu \\
\hline
\end{tabular}

Fonte: Pesquisas realizadas no litoral dos Estados da Bahia, Sergipe, Alagoas e Pernambuco, no período de 2004 a 2006. 


\section{Extrativismo em tempos de globalização?}

A existência de diferentes usos dos recursos naturais, sobretudo nos países do terceiro mundo, estimula uma análise mais detalhada das relações entre os diversos grupos de populações tradicionais ${ }^{8}$ existentes no espaço rural e natureza, com diferentes formas e intensidades de relações com o mercado. A questão que se coloca é: quais as possibilidades de reprodução social desses grupos e dos seus respectivos modos de vida num contexto de crescente subordinação aos ditames do mercado, mas também de valorização de características locais?

Para discutir a questão sugerida, reconhecemos, a priori, quatro posições evidenciadas na literatura. A primeira não questiona o sentido da existência desses povos no contexto global e, pelo contrário, os considera como produtores de saberes e formas de manejo a eles pertinentes e que são essenciais à preservação da biodiversidade (Castro, 1997, p. 165). Ou seja, é um tipo de grupo social que se identifica como um agente do processo de desenvolvimento sustentável que possui baixo impacto sobre o meio ambiente e assim é visto pelo resto da sociedade (Almeida, 2004) sem, no entanto, considerá-lo pela ótica da inserção econômica ou da economia agrícola. A cultura, os modos de fazer e o saber estão no centro dessa posição.

Diferentemente, Shanley et al. (2002) questionam a suposição de que o aumento do comércio de produtos florestais não-madereiros para mercados globais poderia ser promissor mesmo que reconheça a importância do extrativismo para a satisfação das necessidades de grupos em situações desfavoráveis (mulheres e crianças). Assim, segundo os autores, a dificuldade de acesso ao mercado, a baixa densidade dos recursos em muitos casos, a frutificação imprevisível, a perecibilidade dos produtos, dentre outros aspectos indicados, colocam as populações extrativistas em desvantagem quando comparadas a outros grupos que têm possibilidade de regularidade da oferta e de controle da qualidade do produto (cor, tamanho e sabor) no momento da venda. Essa exigência de qualidade, mesmo que concentrada apenas na aparência,, tende a se generalizar,

${ }^{8}$ Sobre populações tradicionais e a problemática do uso desse termo ver: Diegues (1998:87-88), Almeida (2006), Cunha (1999), Hackbart (1999). 
mas ainda não vigora nos dinâmicos mercados regionais nordestino e amazônico de frutas nativas. Neles, a diversidade dos frutos e a irregularidade da oferta no decorrer do ano são consideradas quase que naturais, mesmo que o mercado de polpas supra boa parte da demanda.

Pode-se mencionar, ainda, como terceira tendência, o novo conceito de neoextrativismo, proposto por Rêgo (1999) no Acre, que “... abrange todo uso econômico dos recursos naturais não-conflitante com o modo de vida e a cultura extrativistas. No sentido econômico, neoextrativismo é a combinação de atividades estritamente extrativas com técnicas de cultivo, criação e beneficiamento imersas no ambiente social dominado por essa cultura singular".

Como quarta posição destaca-se a de Homma (1990, 1993), que aponta a inevitável extinção da atividade e afirma: "Apesar de se tratar de recursos naturais renováveis, o que permitiria sua extração ad infinitum, em termos potenciais, são evidenciadas na evolução de sua extração três fases distintas: expansão, estagnação e declínio. Dentre as causas endógenas que levam ao desaparecimento da atividade extrativa estão: (1) aquelas inerentes à extração do recurso em si, dado o desequilíbrio na taxa de regeneração; (2) o processo de domesticação, e (3) o desenvolvimento de substitutos industriais, face à incapacidade do setor extrativo de atender à demanda crescente. $\mathrm{O}$ estudo aponta também variáveis exógenas ao processo extrativo: a expansão da fronteira agrícola e o crescimento populacional que, por requererem maior demanda de terras, destroem a base extrativa, independente de sua rentabilidade” (Homma, 1990, p.5).

Acrescenta ainda: "O extrativismo vegetal constitui uma base de desenvolvimento de vulto bastante frágil, que se justifica mais pelo nível de pobreza dos seus habitantes e do mercado de mão-de-obra marginal. Trata-se de uma economia moribunda, cuja tendência inevitável é seu desaparecimento, à medida que o mercado desses produtos for crescendo (...), o que vai acabar com a economia extrativa (...) [é] a economia do mercado. (...) Qualquer tentativa de apoio ao extrativismo vegetal seria mais no sentido de prolongar essa agonia” (Homma, 1993, p.viii).

Pode ser constatada, em relação ao primeiro ponto apresentado por Homma, a predominância de uma predeterminação que pressupõe o uso predatório generalizado dos recursos vegetais. Sem negar essa probabilidade, caracterizada por Hardin (1968) como "Tragédia dos bens comuns", 
casos concretos de cada sistema de recursos e de cada região devem ser analisados. Autores como Feeny et al. (2001) questionam as suposições de Hardin a partir de uma análise mais detalhada dos regimes de direito de propriedade. No caso do extrativismo de frutas, por exemplo, que foi caracterizado por Homma (1993, p.4) como "extrativismo de coleta", trata-se de um sistema de recursos naturais que fornece um fluxo de unidades de recursos (frutas). O máximo que pode ser retirado é determinado pela oferta de frutas (tamanho da área, número de mangabeiras por área, número de frutas por árvore e dia, etc). Mesmo que sejam retiradas todas as frutas, isso não prejudicará o sistema ou diminuirá a quantidade de unidades da próxima safra (pode haver ainda propagação por sementes de frutos caídos não catados) - diferentemente do que ocorre no caso da sobrepesca, que diminui a disponibilidade futura. Por isso, não existe a idéia de identificar um máximo como, por exemplo, representada pela capacidade de suporte (como o número máximo de cabeças de gado por área) ou a cota de reabastecimento (fluxo máximo de unidades retiradas que não pode ser ultrapassado sem prejudicar o sistema de recursos, a exemplo do caso da pesca ou de águas subterrâneas) ${ }^{10}$. No caso concreto das mangabeiras no litoral nordestino, predomina atualmente a tendência ao aumento dessas árvores, e não há uma ameaça do sistema de recursos pelas próprias catadoras. Ou seja, esse sistema não está sendo prejudicado pela retirada das frutas (Schmitz et al., 2006).

Além disso, pequenos grupos locais e populações maiores são capazes de criar instituições, ${ }^{11}$ elaborar as regras necessárias e garantir o

\footnotetext{
${ }^{9}$ Homma (1993, p.4) distingue entre "extrativismo por aniquilamento ou depredação" (p.ex., extração da madeira ou caça e pesca indiscriminadas) e "extrativismo de coleta" (coleta de produtos extrativos produzidos por plantas ou animais, p.ex., seringa ou castanha-do-pará).

${ }^{10}$ Desde que a cota média de coleta não ultrapasse a cota média de reabastecimento, uma fonte de recursos renováveis pode ser sustentada por tempo indetermindo.

${ }^{11}$ Conjunto de regras de trabalho que determinam, entre outros, os participantes, as ações permitidas ou proibidas, as informações necessárias, a distribuição de benefícios (Ostrom, 1990:51). Deve se distinguir essa visão da abordagem do neo-institucionalismo de outras definições. Uma instituição, no sentido normalmente usado na sociologia, é uma prática social, que se segue de modo quase irreflexivo e que não necessita de elaborações de justificativas, e que alcançou um certo grau de aceitação, por exemplo, o casamento ou a família (Garvía, 1998:55-56). A expressão instituição, no senso comum, significa uma organização, por exemplo, pública, estatal ou religiosa (igreja; instituto de pesquisa, etc.).
} 
respeito dos envolvidos em relação ao uso de bens comuns. Mas fatores externos podem dificultar a permanência desses modos de uso coletivo, como apontado também por Homma. Isso pode ser observado no caso dos remanescentes de mangabeiras que sofrem pressão exercida pelos proprietários que, cada vez mais, as destroem para o cultivo de coqueiros, construção de infra-estruturas turísticas e viveiros de camarão, atividades cuja implantação depende do corte das mangabeiras.

Nesse contexto, a especulação imobiliária e a expansão agrícola levam a um aumento da plantação de mangabeiras em áreas de propriedade privada que pode ser comparada à "domesticação", o segundo ponto da argumentação de Homma.

Em relação ao terceiro ponto apresentado por Homma, o "desenvolvimento de substitutos industriais", pode-se observar uma tendência oposta, o desenvolvimento de processos de construção social dos produtos frescos na agricultura com fortes vínculos com os mercados nacional e internacional, tanto pelo aumento da demanda por produtos naturais e exóticos por parte de estratos de consumidores exigentes e preocupados com hábitos saudáveis, quanto pelos significados de conquistar novos mercados em um contexto globalizado por parte dos empreendedores, como discutido por Mota (2005, p.33).

Interessante observar as ambigüidades nos tempos globais em que, por um lado, a qualidade pela via da quase padronização dos produtos é uma condição para a conquista de mercados e, por outro, há uma valorização do exótico, associado a territórios demarcados e, muitas vezes, a grupos sociais. Ou seja, parece haver espaço para múltiplas inserções. Mesmo que isso seja verdade, o extrativismo como atividade econômica não tem chamado atenção nem da pesquisa, nem das políticas públicas (Porro, 1994), muito embora subsidie a reprodução social de grupos em situação de vulnerabilidade social e dinamize economias locais, além de contribuir para a conservação da biodiversidade e dos saberes e práticas associados ao seu manejo.

\section{Do extrativismo ao consumo}

Em se tratando do extrativismo da mangaba ou de qualquer atividade produtiva no espaço rural, é notável que as novas condições 
de mercados se impõem sobre comunidades locais e suas populações (Cavalcanti, 2003). O que varia, ao longo do tempo ou territorialmente, são as configurações que se tecem. Em todos os casos, no entanto, processos de negociação e conflito subordinam ou autonomizam diferentes atores num jogo de forças em que são construídas estratégias coletivas e individuais para que conquistas obtidas historicamente sejam mantidas - o que nem sempre acontece.

\subsection{Acesso aos recursos: possível para uns, negado para outros?}

Segundo Pereira (2004), parte significativa do litoral norte de Sergipe é secularmente ocupada por grupos humanos que ficaram à margem dos grandes ciclos econômicos. Majoritariamente, são descendentes de escravos negros e de índios que souberam aproveitar as potencialidades e limitações do ambiente natural, criando uma cultura peculiar e rica em formas sustentáveis de utilização dos recursos naturais que garantiram ao longo do tempo a sua reprodução social.

O sistema de acesso à terra, como em outras áreas nordestinas, esteve sempre relativamente livre para um extrativismo ocasional ou condicionado a uma permissão simbólica dada pelo proprietário, sistema que ainda subsiste em alguns espaços. Assim, os entrevistados afirmam que, sob o modo de ocupação do espaço, três tendências se sucederam nessas regiões: vegetação nativa, roças mescladas com vegetação nativa e culturas comerciais (coco, cana, pasto) com espécies nativas (mangabeiras, por exemplo). De modo geral, essa última constituição de paisagem desestruturou mais profundamente os sistemas de uso dos recursos naturais desenvolvidos por populações nativas particularmente nas últimas décadas, com a incorporação dessas áreas ao turismo. Isso tem causado a exclusão de segmentos importantes dessas populações. Mais recentemente, uma quarta tendência caracteriza a paisagem: a expansão desenfreada de infra-estrutura turística e privatização das áreas (sítios, casas de praia) com dois tipos de impactos principais: 1) a quase extinção das mangabeiras em Alagoas e Pernambuco e 2) o aumento do número de mangabeiras em Sergipe e Bahia, especialmente pelo aumento do número de plantas onde elas já existiam. Ou seja, as áreas com mangabeiras foram reduzidas, mas a densidade foi ampliada, como es- 
tratégia das populações nativas que dominam mecanismos de reprodução das árvores frutíferas e por conta da crescente valorização da fruta.

Assim, em Pernambuco e Alagoas as relações estão crescentemente mercantilizadas e as catadoras praticamente não têm mais acesso a áreas próprias ou de uso comum, em decorrência da destruição dos remanescentes principalmente pelo turismo e pela lavoura da canade-açúcar. Em consequência, elas compram a produção no sistema de arrendamento da safra, colhem e vendem para intermediários ou processadoras, sem nenhum tipo de tratamento pós-colheita. Uma ínfima minoria mantém algumas plantas em pequenos estabelecimentos familiares. Pequenas áreas de terras públicas que possuem mangabeiras são também procuradas nas épocas de safra, mas a degradação dos recursos tem inviabilizado o extrativismo.

Nesses estados, praticamente inexiste o relacionamento entre as catadoras que quase não pertencem mais a comunidades tradicionais e tampouco dominam saberes e práticas oriundos da observação das diferentes fases de desenvolvimento da planta. O tempo de colher se desvinculou dos demais e se transformou numa atividade exclusivamente comercial, cujas conseqüências se observam pelas limitadas relações e atores envolvidos nesses processos. Em decorrência, ampliou-se a vulnerabilidade das catadoras que, agora, estão sujeitas a relações imprevisíveis com atores desconhecidos ${ }^{12}$ que se fazem representar pelos caseiros. Como visto, a generalização dos sítios, das casas de praia e de empreendimentos turísticos influenciou fortemente a desagregação do tecido social preexistente e, conseqüentemente, deslocou contigentes dessa população para trabalhar no setor de serviços ou para migrar.

De forma diferente, na Bahia e em Sergipe as formas de acesso aos remanescentes são diversas e muitos dos ingredientes tradicionais subsistem, a exemplo da influência das relações de amizade e compadrio como porta aberta aos recursos. O interconhecimento é um ingrediente fundamental, como observado em sociedades tipicamente camponesas. Assim, os acessos se dão em: 1) áreas públicas e privadas de uso comum; 2) áreas privadas, mas que mediante permissão as catadoras podem desfrutar; 3) pequenos estabelecimentos exclusivos para o extrativismo

${ }^{12}$ Proprietários das áreas, normalmente, profissionais liberais que residem nos centros urbanos e que mantêm sítios ou pequenas propriedades destinadas ao lazer. 
pelos seus proprietários; 4) sítios cujos caseiros fazem parceria com os proprietários; e 5) áreas privadas que são interditadas, mas que os nativos não respeitam. Nessa última forma de acesso, se reconhece que há um conflito latente, mas sem enfrentamentos abertos.

Como visto nos dois estados, há predominância de interações amparadas em relações interpessoais com poucas evidências de ação política para conquistas de acesso definitivo aos recursos. Ou seja, negociações para acesso às áreas privadas são feitas individualmente pelas catadoras com os proprietários, amparadas em regras consuetudinárias que não permitem quebrar galhos ou exaurir as plantas. Conteúdos como amizade, compadrio e parentesco permeiam todas as relações e trazem consigo um caráter de dádiva, dom (Godelier, 1999; Mauss, 2001). Isso aconteceu no caso típico de uma senhora em Sergipe que, à revelia do desejo e dos projetos dos seus filhos, permite que uma área de sua propriedade com cerca de 5.000 plantas seja explorada coletivamente por uma comunidade pobre. Segundo ela, "não pode tirar o pão da boca de tantas famílias”. Trata-se de situação em que “... ao contrário da economia do "toma lá, dá cá", baseia-se em uma denegação do econômico (em sentido estrito), em uma recusa lógica da maximização do lucro econômico, isto é, do espírito de cálculo e da busca exclusiva do interesse material (por oposição ao simbólico), que está inscrito na objetividade das instituições e nas disposições” (Bourdieu, 1996, p.11). A economia do dom visa à acumulação de capital simbólico como reconhecimento, honra, nobreza, etc.

Por um lado, a forma de acesso aos remanescentes de mangabeiras diz respeito à qualidade das relações que se desenvolvem localmente e ao domínio de práticas e saberes somente possíveis por meio do contato cotidiano com os remanescentes. Por outro, no entanto, influencia as estratégias de comercialização que são colocadas em prática e que condicionam maior ou menor ganho. Ou seja, a forma de acesso influencia com quem e que tipo de relação as catadoras manterão em redes de comercialização, além da renda que acumularão no decorrer do processo.

As catadoras que têm acesso garantido aos remanescentes participam de canais de comercialização previsíveis. Elas conseguem atender a demandas, seja de intermediários, seja de consumidores nas feiras ou nas calçadas mais movimentadas das cidades próximas aos lugares em que 
residem. Em ambos os casos, possuem frequência de venda que tende a gerar clientes. Aquelas que só ocasionalmente dispõem de frutas normalmente enfrentam mais riscos e podem não conseguir vender seu produto.

\subsection{Atores e canais de comercialização}

Pelo fato de ser uma fruta altamente perecível e vendida fresca nas épocas de safra no mercado regional, a cadeia produtiva é constituída por um número limitado de atores, quais sejam: catadoras, intermediários, feirantes, processadores (sorveterias e fábricas de polpas ${ }^{13}$ ) e consumidores segundo arranjos que variam freqüentemente.

As catadoras se autodenominam catadoras e assim são reconhecidas socialmente. Suas práticas dependem da forma de acesso ao recurso. Em Sergipe e na Bahia, por terem fácil acesso às plantas, são responsáveis pelo extrativismo, pós-colheita ${ }^{14}$ e venda. Na Bahia, as vendas se dão diretamente pelas catadoras ou por meio de vizinhas. Ambas levam as frutas para municípios próximos.

Em Sergipe, tanto podem vender diretamente nas ruas e feiras próximas aos locais de residência, entregá-las a catadoras que também são vendedoras ou ainda a intermediários que atuam em circuitos mais amplos.

Aquelas que realizam vendas diretas residem perto das cidades e têm facilidade de transporte para o mercado central da capital ou feiras municipais onde vendem por melhores preços para donos de lanchonetes, varejistas, consumidores e intermediários. A venda a diferentes compradores é uma estratégia para diminuir a vulnerabilidade; se um canal falha, o outro funciona. Quando a oferta ainda não está no auge e a fruta ainda é relativamente rara, preferem vender diretamente ao consumidor, porque é muito mais lucrativo (duas ou três vezes mais caro). Em todos os casos, a decisão sobre a quem vender depende muito do que é observado no momento de chegada aos pontos de comercialização, aprendizado que resulta da experiência.

${ }_{13}$ Grande aumento do número de fábricas de polpas em decorrência do aumento da demanda.

${ }^{14}$ Caracterizada pelo acondicionamento das frutas "de vez" em caixas ou baldes revestidos de papel por um período que dura, em média, três dias. Um dos maiores obstáculos é que as mangabas são altamente perecíveis e requerem manuseio e transporte especial. 
Registram-se conflitos em Aracaju pelo fato de a fiscalização ser mais intensa e os feirantes que têm banca dentro do mercado municipal reivindicarem dos fiscais a proibição da venda avulsa na parte externa do mesmo. Para driblar essa situação, a estratégia utilizada pelas catadoras é chegar muito cedo e vender as frutas antes da chegada dos fiscais, o que só ocorre a partir das 7 horas. Assim, vendem parte das mangabas diretamente para os feirantes e parte para outros compradores (consumidores, donos de lanchonete, processadores, etc). Apesar dessa estratégia de venda a múltiplos compradores ser muito freqüente e lucrativa, grande parte das catadoras reconhece que é a mais arriscada, pois pode-se não vender tudo e perder o produto. Algumas avaliam que é melhor entregar as frutas por preços mais baixos do que desperdiçálas. Nessas diferentes decisões, contam a experiência da catadora, a coragem em arriscar e o pertencimento a redes em que vendedor e comprador se conhecem e se escolhem por motivos diversos, como a empatia, a qualidade da mangaba e a camaradagem.

Em todos os casos, existem laços preexistentes que extrapolam o aspecto comercial. Normalmente são vizinhos, parentes ou amigos de longa data a quem as pessoas entregam a sua produção e, posteriormente, recebem o pagamento. Esse tipo de "intimidade" é também característico de populações que ainda partilham experiências de uma vida em comunidade, como observado no Povoado Diogo, em Mata de São João (BA) e Pontal, em Indiaroba (SE).

Pode-se concluir preliminarmente que as catadoras dominam todas as fases do extrativismo e pós-colheita da mangaba em Sergipe e na Bahia. No entanto, no primeiro há uma maior quantidade de atores nos circuitos e uma maior riqueza nas relações sociais pelo fato de diferentes atores entrarem em contato num mesmo contexto, o que facilita o domínio das catadoras sobre todas as fases. Além disso, elas se comportam de modo flexível para lograr uma maior valorização possível do seu trabalho. Outro fator interessante diz respeito às viagens realizadas pelas mulheres para venderem as frutas. Tais situações são importantes momentos de interação social entre elas.

Nos quatro estados, a presença do intermediário não é marcante, mesmo que sejam eles que assegurem a vinculação entre catadoras e processadoras. Não parece haver nenhum tipo de reação das catadoras 
à sua ação. Isso por causa da facilidade que a presença do intermediário lhes assegura ao transportar frutas tão perecíveis e colhidas em quantidades irregulares o que, muitas vezes, não justifica uma viagem para as cidades mais próximas. De qualquer maneira, depender totalmente deses agentes implica dispor menos dos frutos do próprio trabalho.

Há uma diferenciação interna entre os intermediários, conforme mostrou o estudo de caso realizado em Sergipe. O primeiro tipo é constituído por um intermediário que desempenha importante papel, uma vez que busca diretamente as frutas nas casas das catadoras com certa regularidade, muito embora pague os menores preços ${ }^{15}$. O número de visitas às áreas produtoras para a compra dos frutos depende da disponibilidade dos frutos na safra. A depender do volume da produção, as visitas seguintes ficam agendadas. Na época da safra, o intermediário chega a visitar cada catadora três vezes por semana, equilibrando-se entre os diferentes pontos de coleta, a fim de manter os canais em atividade. Esse tipo de ator foi encontrado apenas em Sergipe, onde o mercado da mangaba é mais aquecido em decorrência da grande quantidade produzida e da demanda. Além de recolher as frutas, juntamente com a família, ele faz todo o trabalho de pós-colheita e depois entrega diretamente em sorveterias e fábricas de polpa. Não vende diretamente ao consumidor, tampouco aos feirantes. É um tipo de atuação direcionada para quem exige grande quantidade de frutas.

No segundo caso, a intermediária recolhe os frutos nas casas das catadoras em um carro alugado. As catadoras residem em povoados vizinhos. A mangaba é comercializada fundamentalmente para a fabricação de sorvetes e polpas em Aracaju e Umbaúba (SE). Além disso, ela tem uma banca na feira e vende diretamente aos consumidores, juntamente com outros produtos, como camarão, sururu e aratu.

No caso do terceiro tipo de intermediária, as catadoras levam as mangabas para sua casa, considerando que ela reside próxima às áreas de colheita e que as catadoras não dependem de transporte para entregar a produção. O pagamento às catadoras se dá no ato da entrega se a quantidade for pequena, ou após o retorno da feira.

${ }^{15}$ Normalmente os preços são estabelecidos pelos comerciantes (metade do que é vendido na banca), variam de feira para feira e no supermercado são mais caros. 
Apesar das diferenças nas estratégias de coleta das frutas e de entrega, todos os intermediários lavam, acondicionam, colocam para amadurecer, classificam (separam segundo os níveis de maturação do fruto) e vendem. Além disso, mantêm contato direto com as catadoras e com os processadores.

Em Pernambuco e em grande parte de Alagoas, a venda da mangaba se dá diretamente aos turistas ou outros compradores nas cidades e vilas litorâneas. Em outra parte de Alagoas, há catadoras que entregam a intermediários para venda em Maceió, ou elas próprias comercializam diretamente no mercado municipal da capital.

Em todos os casos, os intermediários são responsáveis pela classificação dos frutos (separam as maduras das "de vez") e acondicionamento para o amadurecimento em caixas de plástico ou em baldes.

Pode-se concluir que o extrativismo e a venda da mangaba são atribuições das mulheres que, cada vez mais, ganham importância entre as atividades desenvolvidas pelas famílias das comunidades tradicionais do litoral do Nordeste. Após o aumento da demanda, as mulheres continuam comandando todas as etapas do extrativismo, dos serviços de pós-colheita e da comercialização, principalmente nas feiras e mercados, e insistem para garantir a sua presença nesses espaços.

\section{Considerações Finais}

Nos últimos anos, houve um aumento substancial do uso de frutas frescas e processadas - dentre as quais a mangaba - para sucos, sorvetes, sobremesas, drinques e pratos sofisticados. A elaboração e o consumo desses produtos se concentram nas cidades e, normalmente, estão sob o domínio de profissionais atentos às novas exigências dos consumidores que, cada vez mais, são ávidos por novidades numa sociedade que parece caminhar para a homogeneização. Por tudo isso, as frutas nativas foram revalorizadas e passaram a fazer parte de uma estratégia de construção social do litoral nordestino como espaço diferenciado para os que querem praticar um turismo fortemente vinculado à cultura local. Pousadas são construídas entre mangabeiras, cartazes produzidos com imagens das frutas frescas, drinques estão disponíveis para aqueles que desejam experimentar, além de geléias 
nos cafés da manhã, etc, compondo uma pauta de originalidades com forte poder persuasivo.

Mesmo assim, é consenso que a fruta circula num mercado regional, embora a partir dos anos 90 venha ocorrendo uma ampliação da sua demanda e ainda não seja possível estimar as fronteiras dessa expansão. Isso porque novos hábitos de consumo são gerados também pelo trânsito de pessoas que experimentam novos sabores nas regiões visitadas e, mais tarde, buscam continuar dispondo desses sabores nos lugares onde residem.

Novidade é a disponibilidade da mangaba na versão polpa em todas as épocas do ano, apesar dos produtos oriundos do extrativismo estarem disponíveis apenas nas épocas de safra. Se por um lado essa disponibilidade provocou a dinamização da cadeia, por outro impulsionou o extrativismo que, em poucos meses (cerca de quatro), tenta atender à demanda dos processadores para todo o ano. Assim, não restam dúvidas de que todos os elos da cadeia produtiva, inclusive o consumo, foram dinamizados de forma semelhante ao ocorrido com as frutas domesticadas (manga, uva, banana, etc.). No entanto, para estas últimas, todas as etapas da produção ao consumo foram "cientificizadas", ao contrário das nativas (cajá, pitanga, mangaba, umbu, araçá, etc). As frutas nativas estão na moda e atendem a novos padrões de consumo mais associados ao seu lugar de produção e à possibilidade de consumir algo de aparência e sabor diferentes, e que também portem uma identidade (por exemplo, o umbu do sertão, mangaba da praia, cajá da mata).

Com tudo isso, essas frutas ainda são originárias do extrativismo e não têm uma qualidade e oferta regular. Isso acarreta problemas para o processamento e para a intensificação da comercialização, seja porque não há previsão de volume, seja porque a qualidade (tamanho, cor, sabor, grau de maturação) é variável, ou ainda porque os procedimentos de póscolheita possuem uma lógica em que frutos com diferentes características são misturados. Exemplo disso é que a mangaba vermelha não é muito aceita para polpas e sorvetes, porque a cor interfere na aparência do produto, mesmo que não modifique seu sabor. Algumas vezes, as catadoras misturam frutos verdes com maduros, o que altera o sabor e amarga os sucos, as polpas, etc. Sem contar que há diferenças entre o sabor da mangaba de inverno e a de verão, sendo que a última tem melhor aparência. 
Se em outros setores os consumidores têm feito valer os seus desejos, no caso da mangaba isso ainda ocorre apenas pela via das processadoras, que exigem frutos com cores mais claras e graus semelhantes de maturação para que as polpas e sorvetes tenham boa aparência e sabor aceitável.

Com processos tão dinâmicos envolvendo atores vulneráveis e em contínua pressão quanto ao acesso aos recursos naturais em ecossistemas frágeis, apresentamos alguma conclusões que evidenciam tendências, potenciais ou problemas, quais sejam:

1. Há uma tendência de "domesticação" (ainda fraca) pelos donos de terra para atender o aumento da demanda sem que, no entanto, seja constituída uma concorrência para o extrativismo. Esta "domesticação" não se distingue muito da prática das catadoras, que também plantam mudas de mangabeira que elas mesmas produzem com as variedades que dispõem. Mas, pelo fato de atender ao crescimento do mercado por meio do plantio sistemático, pode ser considerada a tendência de domesticação prevista por Homma $(1990,1993)$. A crescente demanda dos comerciantes por uma mangaba com uma cor uniforme não pode ser atendida ainda nem pelo extrativismo, nem pelo cultivo, porque são frutas que dependeriam do lançamento de novas variedades;

2. Não se observa uma tendência do extrativismo de coleta “... que leva ao seu aniquilamento a médio e longo prazo” (Homma, 1990, p.4). Isso porque, mesmo que sejam retiradas todas as frutas, a próxima safra não será prejudicada;

3. Atualmente, a ameaça do extrativismo não parte das catadoras, mas de fatores exógenos, como o intenso mercado de terras, a construção de infra-estruturas turísticas e a agropecuária etc, que podem destruir "... a base extrativa, independente de sua rentabilidade" (Homma, 1990:5);

4. Uma estratégia de conservação da biodiversidade deveria ser argumento para garantir que o extrativismo por populações tradicionais seja uma forma de conservação dos recursos e de modos de vida mais sustentáveis. Essa estratégia reforça a idéia de Shanley et al. (2002) e de Rêgo (1999) de apoio ao extrativismo para assegurar a sobrevivência (renda) de grupos vulneráveis;

5. Uma paisagem que mantém as características da restinga pode ser 
mais atraente para turistas do que uma plantação ordenada de mangabeiras ou de cajueiros, ou mesmo uma paisagem semi-urbana com aglomerações de casas de praia.

Para finalizar, do ponto de vista da sustentabilidade dos agroecossistemas, o modelo de exploração pelas comunidades tradicionais não deve ser visto como única solução para o desenvolvimento agropecuário de uma nação ou de uma grande região como a Amazônia (Brush, 1999), mas como uma estratégia que pode ser a mais adequada quando desenvolvida em determinados territórios.

\section{Referências bibliográficas}

ALMEIDA, A.W.B. Terras de quilombo, terras indígenas, "babaçuais livres", "castanhais do povo", faxinais e fundos de pasto: terras tradicionalmente ocupadas. Manaus: PPGSCA-UFAM, 2006. 140p.

ALMEIDA, M. As reservas extrativistas e as populações tradicionais. Entrevista do mês. < http://www.comciencia.br/entrevistas/almeida. htm > . Acesso em: 14/09/2004.

ANDRÉ, M.E.D.A. Etnografia da prática escolar. 4.Ed. Campinas: Papirus, 2000. 128p.

BONANNO, A.; BUSCH, L.; FRIEDLAND,W.;.GOUVEIA, L.; MINGIONE, E. (Eds.). From Columbus to Conagra: the globalisation of agriculture and food. Lawrence: University of Kansas, 1994.

BOURDIEU, P. Marginalia, algumas notas adicionais sobre o dom. Mana. 2 (2), p.7-20, 1996.

BRUSH, S.B. The issues of in situ conservation of crop genetic resources. In: BRUSH, S.B. (Ed.) Genes in the field: on farm conservation of crop diversity. Roma: IPGRI/Ottawa: IDRC/Boca Raton: Lewis Publishers, 1999, p.3-26.

CASTRO, E. Território, biodiversidade e saberes de populações tradicionais. In: CASTRO, E.; PINTON, F. (Orgs.). Faces do trópico úmido: conceitos e questões sobre desenvolvimento e meio-ambiente. Belém: Cejup, 1997, p. 263-283. 
CAVALCANTI, J.S.B. Globalização e agricultura: processos sociais e perspectivas teóricas. Estudos de Sociologia: Revista do Programa de Pós-Graduação em Sociologia/UFPE, 1, 2: 105-118, 1995.

CAVALCANTI, J.S.B. Globalização e processos sociais na fruticultura de exportação do Vale do São Francisco. In: CAVALCANTI, J.S.B. (Org.). Globalização, trabalho, meio ambiente: mudanças socioeconômicas em regiões frutícolas para exportação. Recife: Editora Universitária/UFPE, 1999, p. 123-170.

CAVALCANTI, J.S.B. El "medio ambiente" como objeto de las Ciencias Sociales: un analises basado en los estudios de globalización en los sistemas agroalimentarios. In: BENDINI, Mónica; CAVALCANTI, J.S.B.; MURMIS, M.; TSAKOUMAGKOS, P. (Orgs.). El campo en la sociología actual: una perspectiva latinoamericana. Buenos Aires: Editorial La Colmena, 2003, p.157-176.

CUNHA, M.C. Populações tradicionais e a convenção da diversidade biológica. In: Estudos Avançados 13 (36), p.147-163, 1999

DIEGUES, A.C.S. O mito moderno da natureza intocada. 2.Ed. São Paulo: Editora Hucitec, 1998. 169p. < Original: Nupaub-USP, 1994 >

FEENY, D.; BERKES, F.; MCCAY, B.J.; ACHESON, J.M. A tragédia dos comuns: vinte e dois anos depois. Trad. André de Castro C. Moreira. In: DIEGUES, A.C.; MOREIRA, A.C.C. (orgs.). Espaços e recursos naturais de uso comum. São Paulo: NUPAUB/LASTROP-USP, 2001, p.17-42. < Original: $1990>$

FRIEDLAND, W.H. The new globalization: the case of fresh produce. In: BONANNO, A.; BUSCH, L.; FRIEDLAND,W.;.GOUVEIA, L.; MINGIONE, E. (Eds.). From Columbus to Conagra, Lawrence, University Press of Kansas, 1994.

GARVÍA, R. Conceptos fundamentales de sociología. Madrid: Alianza Editorial, 1998. 115p.

GODELIER, M. The enigma of the gift. Trad. N. Scott. Cambridge: Polity Press, 1999.

HACKBART, R. A criação de unidades de conservação dependerá 
de lei. 1999. <http://www.pt.org.br/assessor/senuc.htm > Acesso 02.03.2007.

HARDIN, G. The tragedy of the commons. Science 162:1244-8, 1968.

HOMMA, A.K.O. A dinâmica do extrativismo vegetal na Amazônia: uma interpretação teórica. Belém: Embrapa-CPATU, 1990. 38p. (Documentos 53).

HOMMA, A.K.O. Extrativismo vegetal na Amazônia: limites e oportunidades. Brasília: Embrapa-SPI, 1993. 202p.

LAMNEK, S. Qualitative Sozialforschung. Band 2: Methoden und Techniken. 3.ed. Weinheim: Beltz, Psychologie Verlags Union, 1995. 440p.

MARSDEN, Terry K. Globalização e sustentabilidade: criando espaço para alimentos e natureza. In: Cavalcanti, J.S.B. (Org.), Globalização, trabalho, meio ambiente: mudanças socioeconômicas em regiões frutícolas para exportação. Recife: Editora Universitária da UFPE, 1999, p.25-46.

MAUSS, M. Sociologie et anthropologie. 9.Ed. Paris: Quadrige/Presses Universitaires de France, 2001.

McLUHAN, M. The Gutenberg Galaxy. London: Routledge, 1962.

MOTA, D.M. Trabalho e sociabilidade em espaços rurais. Fortaleza: Banco do Nordeste, Embrapa Tabuleiros Costeiros, 2005. 256p. (Série Teses e Dissertações 1).

MOTA, D.M.; SILVA JÚNIOR., J.F. Populações tradicionais e formas coletivas de gestão das áreas de ocorrência de mangabeira. Raízes, Campina Grande, v.22, n.2, p.225-233, jul./dez. 2003.

MOTA, D.M.; SILVA JUNIOR, J.F.; GOMES, J.B.V. Lógicas de reprodução social de uma população tradicional de catadores de mangaba no litoral Sul sergipano. In: Simpósio Brasileiro sobre a Cultura da Mangaba, 1, 2003, Aracaju. Anais. Aracaju: Embrapa Tabuleiros Costeiros, 2003. (CD).

MOTA, D.M.; SILVA JÚNIOR., J.F.; SCHMITZ, H. Os catadores de mangaba e a conservação da biodiversidade no território Sul sergipano. In: Congresso Brasileiro de Economia e Sociologia Rural. 43, Ribeirão Preto, 2005, Anais, Brasília: SOBER, 2005. 
OSTROM, E. Governing the common: the evolution of institutions for collective action. Cambridge, New York: Cambridge University Press, 1990.

PEREIRA, E.O. Criação de Projeto de Assentamento sob Condições Especiais em Área Frágil. In: Sociedade Brasileira de Sistemas de Produção, 6, 2004, Aracaju. Anais. Aracaju: SBSP, EMBRAPA-CPATC, UFS, 2004. (CD).

PORRO, R. As Reservas Extrativistas do Babaçu. In: A Amazônia Brasileira em Foco. II Seminário Maranhense de Defesa e Desenvolvimento da Amazônia. CNDDA, no.22, ano 28, Rio de Janeiro, 1994.

RÊGO, J.F. Amazônia: do extrativismo ao neoextrativismo. Ciência Hoje, v.147, março 1999. 6p. < http://cienciahoje.uol.com.br/view/349> Acesso: 21.11.2006.

SCHMITZ, H.; MOTA, D.M.; SILVA JÚNIOR, J.F. Gestão coletiva de bens comuns e conflito ambiental: o caso das catadoras de mangaba. In: Encontro da Associação Nacional de Pós-Graduação e Pesquisa em Ambiente e Sociedade (Anppas), 3, Brasília, 2006.

SHANLEY, Patrícia; LUZ, Leda; SWINGLAND, Ian. A frágil promessa de um mercado distante: um levantamento sobre o comércio de produtos florestais não-madeireiros em Belém. Belém: CIFOR, 2002. 24p. (mimeografado). < Original: Shanley, P.; Luz, L.; Swingland, I. The faint promisse of a distant market: a survey of Belém's trade in non-timber forest products. Biodiversity and Conservation, 11:615-636, 2002. >

SILVA JÚNIOR, J. F.; MOTA, D. M.; GOMES, J. B. V. Representações de uma população tradicional de catadores acerca do extrativismo da mangaba no litoral sul de Sergipe. In: Simpósio Brasileiros sobre a Cultura da Mangaba, 2003, Aracaju: Embrapa Tabuleiros Costeiros, 2003. Disponível em CD-ROM. 